\title{
Desafíos en la protección de la libertad de expresión en México: 20 años de avances con pobres resultados
}

\section{Challenges in protecting freedom of expression in Mexico: 20 years of progress with poor results}

\author{
Dr. Salvador De León Vázquez \\ Universidad Autónoma de Aguascalientes. México. \\ salvador.deleonv@edu.uaa.mx \\ https://orcid.org/0000-0002-7859-0480

\begin{abstract}
Resumen
Este ensayo revisa las condiciones de la protección a la libertad de expresión en el contexto de dos décadas de alternancia partidista en el Poder Ejecutivo Federal de México. En clave evaluativa se consideran tres elementos de análisis: 1) avances en la legislación, 2) condiciones reales del ejercicio de la libertad de expresión, y 3) planteamientos desde el espacio local. El método de análisis consiste en la revisión documental de la legislación sobre comunicación social en México considerada como el resultado de un amplio proceso desarrollado durante los últimos 20 años en contraste con datos de los riesgos de ejercer la libertad de expresión en México. Los resultados muestran una intensa adecuación legislativa y de políticas públicas, sin embargo, los datos disponibles demuestran que la implementación de esos mecanismos no ha sido significativa ante la permanencia de problemas de consecuencias fatales.
\end{abstract}

\section{Abstract}

This essay reviews the conditions of protection of freedom of expression in the context of two decades of partisan alternation in Mexico. In evaluative terms, three elements of analysis are considered: 1) advances in legislation, 2) real conditions of the exercise of freedom of expression, and 3) approaches from the local space. The method of analysis consists of the documentary review in contrast to data on the risks of exercising freedom of expression in Mexico. The results show an intense legislative and public policy adaptation, however, the available data shows that the implementation of these mechanisms has not been significant in the face of permanent problems with fatal consequences.

Palabras clave: Libertad de Expresión; Legislación de las comunicaciones; Derecho a la Información; Periodismo.

Keywords: Freedom of Expression; Legislation; Right to Information; Journalism. 


\section{Introducción}

La propuesta de este artículo es la de realizar una evaluación de los mecanismos de protección a la libertad de expresión, los cuales necesariamente deben ser jurídicos para garantizar su cumplimiento, a la par que se contrasta con las dificultades de quienes tratan de ejercerla profesionalmente, en un ambiente altamente peligroso evidenciado por las agresiones y crímenes contra comunicadores.

Para ello, se recuperan algunos datos históricos en la materia correspondientes a los últimos 20 años para establecer elementos evaluativos, se analizan los instrumentos legales vigentes y se contrasta con datos empíricos vinculados con la actividad periodística considerada como una de las modalidades más importantes del ejercicio de la libertad de expresión.

El artículo consta de cuatro secciones. En la primera se ofrece una revisión de antecedentes y puntos de partida, identificando el cuerpo de conocimientos relacionados con la regulación de la libertad de expresión en México. La segunda corresponde a la metodología utilizada. La tercera muestra los resultados del análisis. La cuarta sección presenta la discusión integradora.

\section{Antecedentes. La Alternancia como el Punto de Quiebre de las Regulaciones en Comunicación}

Después de 70 años del mantenimiento de un régimen de partido único, México arribó al año 2000 con un pasivo evidente en materia de protección a los derechos y libertades de la comunicación y la información. Varios autores identificaron, en su momento, que la problemática tenía su origen -y arraigo- en las alianzas sólidamente construidas a lo largo de la segunda mitad del siglo XX entre las cúpulas del poder político y el poder mediático (Bohmann, 1994; Fernández, 1993). Era una dinámica en la que los medios de comunicación constituyeron un sector corporativo más del Partido Revolucionario Institucional (PRI) y del presidencialismo mexicano, prestándose a la fabricación de una representación oficial de la realidad pública (Hallin, 2000). Se alimentó una serie de relaciones perversas con fines del mantenimiento del poder político, usando como arma la representación mediática del acontecer (Trejo, 1996). Esto constituyó un modo de subordinación de la prensa al poder político (Carreño, 2000) que algunos concibieron como una mediocracia debido al poder fáctico que los empresarios de los medios acumularon gracias a todas esas décadas de servilismo político (Esteinou, 2015).

En ese contexto, el año 2000 representó la culminación de un proceso de ruptura. Un modelo heurístico, aunque dicotómico, que sintetiza ese proceso es el que muestra los cambios económicos, políticos y socioculturales y sus afectaciones sobre la comunicación pública en México y que corresponde al periodo finisecular y la llegada de la alternancia. El régimen de partido único instituyó un modelo económico de sustitución de importaciones y generó un relato mediático del acontecer público oficialista y cerrado a la discrepancia. Por su parte, el colapso paulatino de ese régimen abrió la posibilidad de la alternancia partidista en distintos niveles de gobierno hasta alcanzar el federal. De manera previa a la alternancia -y presumiblemente uno de los factores que la impulsó-, se adoptó una economía de mercado abierto bajo esquemas neoliberales. Esa situación debilitó necesariamente al Estado en favor del mercado y la sociedad civil, permitiendo también la pérdida del control mediático y generándose descentramientos en los relatos sobre lo público y sus protagonistas (De León, 2011).

El año 2000 fue el momento en el que confluyeron condiciones históricas que hicieron posible un cambio, producto de procesos sociales complejos echados a andar tiempo atrás. Se trataba del 
resultado de luchas y reivindicaciones sociales, disputas por el poder político. También influyeron factores exógenos como la exigencia de democratización planteada desde el exterior y el cumplimiento de ciertos requisitos de libertad y estabilidad para el intercambio económico (Aguilar, 2005; Camp, 2006; Levy \& Bruhn, 2006).

Gutiérrez (2005) ofrece un análisis pormenorizado de las luchas emprendidas por diversos actores en la última década del siglo XX para ampliar el marco jurídico sobre la comunicación social, que en ese momento aparecía limitado y cuestionado. De acuerdo con este autor, el proceso inició en 1995 con la reforma del Estado que incluía la elaboración de una ley de comunicación social, la revisión de la Ley de Imprenta y la Ley Federal de Radio y Televisión, así como la reglamentación del derecho a la información. Al final, ninguna de esas acciones se llevó a cabo.

El primero de varios avances en la implementación de mecanismos para hacer exigibles los derechos de la información y la comunicación ocurrió dos años después de la alternancia, con la promulgación de la primera Ley Federal de Transparencia y Acceso a la Información en 2002 (Gutiérrez, 2005; J. M. Ramírez, 2008). En el proceso, existió un conjunto de debates que finalmente fueron conciliados. Uno de ellos consistía en la dificultad de establecer mandatos para exigir a los medios de comunicación el cumplimiento al derecho a la información, en un Estado en donde los empresarios mediáticos habían alcanzado un poder fáctico considerable. Gutiérrez (2005) sugiere que la salida encontrada por el gobierno federal, de exigir el acceso a información pública gubernamental, era una solución políticamente correcta al evitar confrontarse con los empresarios de los medios. Se generó un mecanismo a través del cual los propios medios y los ciudadanos podrían auscultar y escudriñar al gobierno federal. De esta manera, según el autor, los actores políticos involucrados evitaron la pérdida de la rentabilidad política ante los empresarios mediáticos.

Otro de los debates se dio en el terreno de su gestación, puesto que al principio existieron dos propuestas diferentes. Una de ellas, la más completa a juicio de Ramírez (2008), fue la que surgió de la sinergia de organizaciones civiles, académicos y periodistas conocidos como el Grupo Oaxaca. Sus integrantes presentaron un documento de vanguardia que fue apoyado y presentado por legisladores del opositor Partido de la Revolución Democrática (PRD) como iniciativa de ley en el congreso federal. Al mismo tiempo, el Partido Acción Nacional (PAN) que ocupaba el poder federal, promovió su propia iniciativa de corte más conservador. Ambas iniciativas fueron discutidas y, finalmente, la Ley Federal de Transparencia y Acceso a la Información Pública aprobada fue una combinación de las dos.

En este contexto, comenzó el proceso paulatino de dos décadas en las que se han ido elaborando regulaciones de la comunicación social en México. En las siguientes secciones se ofrece un análisis e interpretación de las condiciones en las que ello ha ocurrido. Se trata de un análisis diacrónico por medio del cual se pretende dar cuenta del robustecimiento del cuerpo jurídico en la materia, y sus problemáticas.

\section{Metodología}

Mediante una revisión documental, se reconstruyó el proceso de formulación de un cuerpo de instrumentos legales relacionados con la comunicación social que son el producto de recomposiciones y replanteamientos de las últimas dos décadas, que corresponden precisamente a la alternancia partidista. 
Esa reconstrucción es utilizada como un marco de contexto que explica la existencia de las leyes vigentes en la materia, tanto en el plano federal como en el estatal. Particularmente se han revisado las leyes estatales o locales mediante un análisis argumentativo o formal. La decisión de elegir este corpus tiene que ver con tres aspectos relacionados entre sí.

El primero consiste en el hecho de la amplia elaboración de trabajos que analizan la legislación federal sobre comunicación social (Álvarez, 2018; Arroyo, 2015; Brambila, 2018; Gómez, 2018; Hincapié \& López, 2018; Huerta \& Becerra, 2016; Lay, 2013; Torres, 2011), frente al casi nulo abordaje de la legislación subnacional sobre comunicación social en México.

El segundo es una reflexión que funciona como hipótesis, en el sentido de que las discusiones sobre la reglamentación de la transparencia, el acceso a la información, la protección de los periodistas, la regulación de la publicidad gubernamental, entre otros temas, ha permeado a las preocupaciones locales fructificando en los marcos legales existentes en ese plano; en ocasiones por la obligación de alinearse con los marcos federales como en el acceso a la información y protección de datos personales, pero en otras por el impulso de proteger los derechos civiles relacionados con la información y comunicación, lo que hace necesario abordar esa esfera.

El tercer aspecto corresponde a la necesidad de reconocer que para realizar un abordaje responsable sobre las condiciones de la protección a la libertad de expresión en México, no basta tomar en cuenta el plano federal, sino que es necesario identificar como ese plano interactúa con lo local, dando cuenta de una nueva categoría en la que se formalizan las políticas públicas, el espacio subnacional (Augusto et al., 2017; Ríos \& Soto, 2017; Rolandi \& Merello, 2017), lo cual ayuda a explicar por qué hay distintos niveles de modernización y avance en las diferentes regiones del país (González \& Echeverría, 2017).

El análisis argumentativo o formal consiste en separar el discurso en enunciados para identificar sus relaciones estructurales y temáticas (Thompson, 1998). Se han tomado como unidades de análisis los instrumentos legales, y se han establecido cinco categorías de análisis: 1) Rendición de cuentas y protección de datos; 2) Comunicación gubernamental; 3) Libertad de expresión y derechos de las audiencias; 4) Regulaciones sobre los medios y las industrias audiovisuales; 5) Derechos digitales y gobierno electrónico, digital y abierto. Estas categorías resultaron de la integración sintética de tres criterios teóricos.

El primero de esos criterios consiste en la tipología de legislación sobre los sistemas mediáticos en los Estados occidentales establecida por Hallin \& Mancini (2004): 1) leyes sobre la difamación, privacidad y derecho de réplica, 2) leyes sobre la incitación al odio, 3) leyes sobre el secreto profesional y la conciencia de los periodistas, 4) leyes sobre el acceso a la información gubernamental, 5) leyes que regulan la concentración, propiedad y competencia de los medios, 6) leyes que regulan las campañas electorales y la comunicación política y 7) leyes sobre las licencias y concesiones de radiodifusión.

El segundo es el instrumento evaluativo del desarrollo mediático por parte de la UNESCO (2010) en lo correspondiente al marco legal. La UNESCO divide la categoría del marco jurídico en: a) marco jurídico y político, b) sistema para regular los medios de comunicación, c) leyes sobre la difamación y otras restricciones legales sobre periodistas y d) censura.

El tercero procede de los mandatos establecidos en los artículos sexto y séptimo constitucionales en los cuales se reconocen los derechos y libertades de la información y la comunicación. Esos derechos y libertades consisten en: a) derecho de acceso a la información, b) libertad de difundir 
las ideas, c) acceso a las tecnologías de información y comunicación, servicios de radiodifusión y telecomunicaciones, d) protección de los datos personales, e) derechos de los usuarios de las telecomunicaciones y las audiencias, f) prohibición de la censura.

Considerando esos tres criterios teóricos, se ha efectuado una revisión diacrónica de los procesos legislativos relacionados con las formulaciones jurídicas sintetizadas en las cinco categorías analíticas mencionadas. Para auxiliarnos en esta tarea se ha usado el software Nvivo 12.

\section{Resultados. Grandes avances, pobres resultados en la defensa de la libertad de expresión en México}

\subsection{Tres momentos de definición jurídica}

En las últimas dos décadas, es posible identificar tres grandes momentos en lo que se refiere a la consolidación de los derechos y libertades de la información y la comunicación. El primero de ellos, vino de la mano de la alternancia política en el nivel federal. Consiste en la promulgación de la Ley Federal de Transparencia y Acceso a la Información Pública Gubernamental en el año 2002. Representó el término de una larga espera para tener, por primera vez, un instrumento legal específico sobre el derecho a la información. Por mandato de esta misma ley, se instituyó el organismo autónomo Instituto Federal de Acceso a la Información (IFAI), que sería el encargado de garantizar su cumplimiento y dirimir aspectos problemáticos.

Un asunto poco comentado en la literatura especializada es que, con la promulgación de esta ley en el plano federal, cada estado de la República Mexicana tuvo la obligación de elaborar su propia ley estatal, los mecanismos para hacerla efectiva, y los organismos autónomos para vigilar su cumplimiento. Éstos también han cambiado con el tiempo y las reformas posteriores.

El segundo momento clave lo constituyó la reforma electoral del 2007. Su resultado fue el Código Federal de Instituciones y Procedimientos Electorales (COFIPE) que estableció fuertes candados a las campañas electorales en radio y televisión. Por ejemplo, la cancelación de la compra de espacios y la utilización única de los tiempos oficiales asignados al Estado, así como el monitoreo de los espacios publicitarios y noticiosos para identificar sesgos en la cobertura (Ramos, Márquez, \& Sánchez, 2008). Aunque la reforma fue el resultado de un impulso de décadas atrás, no cabe duda que las cuestionadas elecciones federales del 2006, así como las fuertes sumas de recursos dirigidas a los medios electrónicos en las campañas electorales, fueron factores que determinaron su consolidación.

Un solo ejemplo basta para la comprensión cabal de la aseveración anterior. El financiamiento público que los partidos políticos recibieron durante las campañas electorales federales de 2006 fue de un poco más de dos mil millones de pesos. De esa cantidad, el 95\%, más de 1,900 millones de pesos, se gastó en los medios electrónicos (radio y televisión). Además, las confederaciones y asociaciones de empresarios y de industriales desean seguir teniendo especial influencia en los comicios, precisamente a través de propaganda pagada en los medios electrónicos. (Carpizo, 2008, p. 34)

Esta reforma electoral ocurrió en el marco más amplio de la reforma del Estado. Incluyó también algunos ajustes a la Ley de Transparencia y Acceso a la Información Pública Gubernamental para establecer condiciones más abiertas para la consulta de información. Gracias a esta reforma, ya no sería necesario identificarse ni fundamentar el uso de la información solicitada. También se estableció la figura positiva ficta, para fijar plazos en las respuestas a las consultas de información. Asimismo, se adicionó un párrafo en el artículo 134 constitucional para normar la propaganda gubernamental. 
El poder fáctico de las empresas televisivas resultó disminuido en el episodio conocido como la "Ley Televisa". Consistió en la presentación de una iniciativa de reforma a la Ley Federal de Radio y Televisión, en 2006. Se pretendía establecer el predominio de los radiodifusores sobre la provisión de servicios de telecomunicaciones triple play (televisión, telefonía e internet), desplazando a las empresas de televisión por cable que ya ofrecían estos servicios. A pesar de su aprobación en las dos cámaras del Congreso, un conjunto de senadores promovió una acción de inconstitucionalidad de la reforma ante la Suprema Corte de Justicia de la Nación, invalidándola de esta manera (Esteinou, 2009; Lay, 2013; Madrazo \& Zambrano, 2007).

El tercer gran momento corresponde a la reforma constitucional del 2013, que modificó sustancialmente los artículos sexto y séptimo, los cuales tutelan los derechos y libertades de la información y la comunicación de los mexicanos. Esta reforma tuvo como antecedente el movimiento social \#YoSoy132, encabezado por jóvenes universitarios. Tomaron como una de sus causas a la democratización de los medios de comunicación, exigiendo acabar con la fuerte influencia política de las televisoras. Éstas eran consideradas como "el gran elector" (Cantú, 2005), por ser capaces de cargar la balanza en los procesos electorales a favor de algún candidato. Aunque el movimiento fue un antecedente de peso, es necesario señalar la existencia de influencias internas y externas ejercidas sobre el Estado para modernizar y abrir su esquema de regulación de los medios y las telecomunicaciones (Huerta \& Becerra, 2016).

Como consecuencia de esta reforma, fueron abrogadas la Ley Federal de Transparencia y Acceso a la Información Pública Gubernamental y la Ley Federal de Radio y Televisión. En su lugar, se promulgaron una nueva Ley Federal de Transparencia y Acceso a la Información Pública y la Ley Federal de Telecomunicaciones y Radiodifusión. Ésta última se complementa, en lo relativo al sector industrial de las telecomunicaciones, por la Ley de Competencia Económica. También se expidió la Ley General de Protección de Datos Personales en Posesión de Sujetos Obligados. Algunos años más tarde, en 2018, se expidió la Ley General de Comunicación Social para establecer el marco reglamentario del artículo 134 constitucional. Se puede decir que este tercer momento nos ha dotado de un gran paquete legal que otorga certidumbre jurídica a los principales procesos comunicacionales del país.

Sin embargo, en esta reforma, y en la elaboración de las leyes reglamentarias, estuvieron presentes las viejas discusiones sobre los problemas históricos como la alta concentración que da origen a un oligopolio mediático. Esto genera un mercado controlado por la competencia reducida de una élite empresarial dominante que, además, ha exhibido una gran capacidad para el cabildeo político y la salvaguarda sus intereses económicos (Huerta \& Becerra, 2016).

Las elaboración de las leyes reglamentarias formuló un nuevo marco de relaciones centrado en cuatro aspectos: 1) el reconocimiento de derechos fundamentales de las audiencias, del acceso a la información, a los medios, a las redes digitales y a la rendición de cuentas; 2) un marco institucional mediante la creación de organismos autónomos, tribunales especializados y un sistema público de radiodifusión del Estado mexicano; 3) la regulación de la competencia y la convergencia considerando la inversión extranjera, la preponderancia económica, nuevas obligaciones como el must carry y must offer, la transición a la televisión digital, entre otras cosas; y 4) el fortalecimiento del Estado como regulador y operador del espectro radioeléctrico, la banda ancha y las redes (Huerta \& Becerra, 2016).

En contraparte, la nueva legislación también faculta al Estado para disminuir los derechos ciudadanos. El título octavo de la Ley Federal de Telecomunicaciones y Radiodifusión titulado "de la colaboración con la justicia"; bajo el argumento de la seguridad pública, obliga a los concesionarios de telecomunicaciones a revelar contenidos, datos y localización de los equipos móviles, e incluso interrumpir el servicio. Esto se relaciona con el espionaje de los ciudadanos por parte del Estado, particularmente en las movilizaciones masivas, como fue el caso del movimiento \#YoSoy132. Esto puede ser interpretado como una estrategia estatal para desactivar los 
movimientos tecnopolíticos que "no utilizan la tecnología como algo complementario sino sinérgico. Lo que ocurre in situ y online son dimensiones imbricadas de un mismo fenómeno" (Rovira, 2017, p. 137).

Por su parte, la Ley General de Comunicación Social tiene por objetivo regular el gasto gubernamental en publicidad. Sin embargo, la ley presenta vacíos importantes como la falta de mecanismos claros sobre la distribución de los recursos públicos entre los medios. Esto impide exigir claridad en la aplicación de esos recursos. Otro asunto problemático es la obligación de inscribirse en un registro de medios a cargo de la Secretaría de Gobernación, como requisito para poder recibir recursos federales, lo cual puede interpretarse como una forma de control gubernamental sobre los medios de comunicación.

\subsection{La permanente crisis en el real ejercicio de la libertad de expresión}

A pesar de los avances innegables en materia jurídica, una crisis multifactorial de la libertad de expresión es visible. Se trata de una condición que es verificable, puesto que se ha expresado en forma de agresiones en contra de los informadores y los medios de comunicación críticos, así como de ciudadanos en ejercicio de sus derechos de difusión a través de las redes digitales. Es, el resultado de dos tendencias que son contrarias entre sí, lo cual puede parecer paradójico y, sin embargo, demostrable en las investigaciones empíricas.

Por un lado, está la tendencia hacia el autoritarismo ejercido por los cacicazgos locales, representados por los gobernadores estatales (Espino \& Mendoza, 2015). Estos actores suelen limitar el margen de crítica de los medios a través de medidas de presión para el mantenimiento del oficialismo. Sus estrategias comprenden el retiro de la publicidad gubernamental, la instalación de procesos judiciales en contra de los informadores, las amenazas e incluso la violencia directa. Por el otro lado, existe la tendencia hacia la debilidad del Estado, que pierde el monopolio del uso de la fuerza legítima para la preservación del orden, debido a que otros agentes ilegales y paralegales ejercen violencia -muchas de las veces extrema- (Reguillo, 2013), en contra de los ciudadanos y, particularmente, de grupos incómodos para sus fines como la prensa.

Respecto a la primera tendencia, un cuerpo sólido de trabajos empíricos muestra los detalles de la limitación a la libertad de expresión por parte de los caciques locales. El elemento central consiste en convenios publicitarios celebrados con las cúpulas mediáticas. Hay evidencia de que situaciones similares se reiteran en entidades como Nayarit (Orozco, 2007), Sinaloa (Rodelo, 2009), Aguascalientes (De León, 2011), Michoacán (González, 2013), Querétaro (Espino \& Mendoza, 2015), Veracruz (Del Palacio, 2015), Jalisco (Hernández, 2016), Baja California (Merchant, 2017), el Estado de México (Maldonado, 2018), y seguramente en el resto de las entidades.

Los convenios publicitarios se fincan sobre el hecho de que la publicidad política es cobrada de manera mucho más onerosa que la publicidad comercial (De León, 2003). En todos los estudios disponibles se coincide en que es la principal vía de subsistencia de los medios locales. Sin embargo, este tipo de publicidad política implica mucho más que la publicación de información oficial: obliga a una cobertura favorable para las instancias que la contratan y al ocultamiento de información; también a la censura y a la autocensura, lo que es una vulneración directa de la libertad de expresión. Además, opera en la opacidad. Es difícil acceder a un documento original, por lo regular sus cláusulas suelen prohibir a los trabajadores de los medios la sola mención de su existencia.

Con relación a la segunda tendencia, es ya un lugar común decir que México es el país más peligroso para ejercer el periodismo. La UNESCO (2018) reconoció que durante 2017 y 2018 nuestro país ocupó el primer lugar en asesinatos de periodistas en el mundo. Independientemente 
de la comparación global, las agresiones contra los informadores constituyen ya un rasgo característico del periodismo mexicano. La figura 1 es un histograma comparativo de los crímenes perpetrados contra informadores mexicanos de acuerdo con la Fiscalía Especial para la Atención de Delitos contra la Libertad de Expresión (FEADLE, 2020) y la organización civil internacional Article 19 (Article-19, 2020).

Figura 1. CIFRAS DE ASESINATOS DE PERIODISTAS EN MÉXICO, SEGÚN LA FEADLE Y ARTICLE 19, 2000-2020

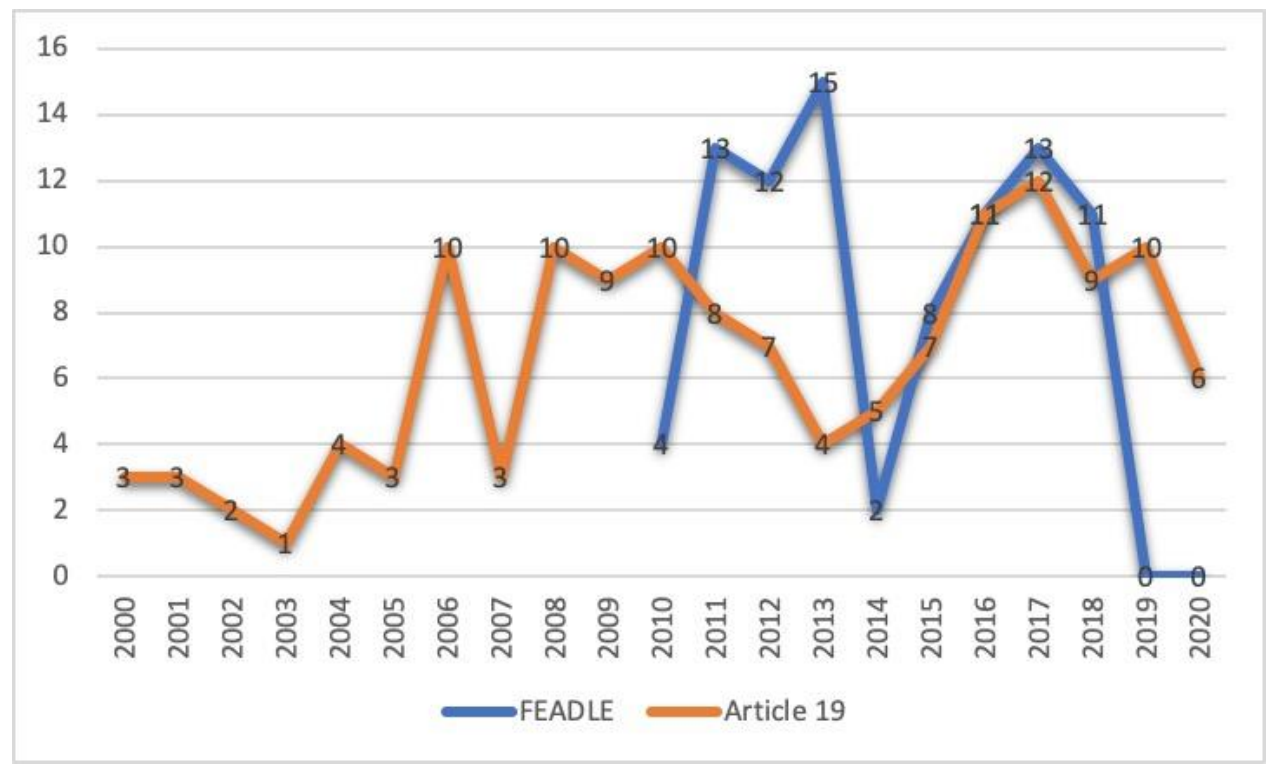

Nota. La FEADLE se instaló en el año 2010, motivo por el cual los datos inician en ese año. Fuente. Elaboración propia con datos de la FEADLE (2020) y Article 19 (2020) complementado con nota del diario La Jornada para el año 2020 ("Van seis periodistas asesinados en México en 2020", 2020).

La figura 1 muestra el contraste de las cifras oficiales de la FEADLE con las provistas por Article 19. Se observa que los conteos difieren ante la falta de sistematicidad. Un problema importante es la ausencia de castigo a los perpetradores, situación que produce un clima de impunidad ante las agresiones sufridas. De acuerdo con las estadísticas oficiales, de 5,151 indagatorias relacionadas con agresiones contra periodistas contabilizadas hasta junio del 2020, solamente en 210 se ejerció acción penal, (FEADLE, 2020). La violencia contra los informadores no se agota en el asesinato, si bien éste representa su forma más extrema. La FEADLE (2020) reconoce 36 delitos contra periodistas -además del asesinato- que van de las amenazas al secuestro, pasando por procedimientos judiciales para presionarlos, censurarlos u obligarlos a revelar sus fuentes informativas.

La violencia contra periodistas en México generó una serie de dinámicas entre las que se encuentran las siguientes:

1. Se ha reconocido que la violencia contra los informadores proviene de dos grandes aparatos, el Estado a través de sus agentes y la delincuencia organizada. Los periodistas se encuentran entre dos frentes que los vulnera y los obliga a callar (Brambila, 2018; Cepeda, 2017; Del Palacio, 2018; Ramírez, 2018; Rodelo, 2009).

2. Ante la inacción de las empresas periodísticas que los adscriben y del Estado, el sector de periodistas más afectado se ha organizado en redes autogestivas para aprender a protegerse. Es la lógica de la subpolítica (Beck, 2006), es decir, actuar desde un espacio extrainstitucional para atender por sí mismos los problemas que las instituciones no 
resuelven (De León, Bravo, \& Duarte, 2018; González de Bustamante, 2014; Martínez \& Ramos, 2020).

3. Ante las presiones de la sociedad civil organizada, de las redes de periodistas y de organismos internacionales, el gobierno federal expidió, en 2012, la Ley de Protección a Personas Defensoras de los Derechos Humanos y Periodistas, que contempla un mecanismo de protección y sus formas de operación. En la práctica, ha demostrado tener muchas fallas derivadas, principalmente, de la falta de voluntad política para destinar recursos y efectuar una protección eficaz (González \& Reyna, 2019).

En lo local, doce entidades federativas asumieron también la tarea de formular normas jurídicas para atender la violencia contra periodistas desde sus ámbitos de competencia (ver tabla 1). Sea por rentabilidad política, por presiones sociales o por una auténtica preocupación ante la problemática, estas entidades elaboraron sus propias leyes locales, replicando en su mayoría la estructura y elementos de la ley federal.

Tabla 1. LEYES ESTATALES DE PROTECCIÓN A PERIODISTAS Y DEFENSORES DE DERECHOS HUMANOS

\begin{tabular}{|c|c|c|}
\hline Entidad federativa & Nombre de la ley & $\begin{array}{c}\text { Fecha de entrada } \\
\text { en vigor }\end{array}$ \\
\hline Ciudad de México & $\begin{array}{l}\text { Ley para la protección integral de personas } \\
\text { defensoras de los derechos humanos y } \\
\text { periodistas de la Ciudad de México }\end{array}$ & $\begin{array}{r}10 \text { de agosto de } \\
2015\end{array}$ \\
\hline Coahuila & $\begin{array}{l}\text { Ley para la protección de las y los periodistas } \\
\text { para el estado de Coahuila de Zaragoza }\end{array}$ & 18 de julio de 2014 \\
\hline Durango & $\begin{array}{l}\text { Ley estatal para la protección de periodistas y } \\
\text { personas defensoras de los derechos humanos }\end{array}$ & $\begin{array}{r}25 \text { de diciembre de } \\
2014\end{array}$ \\
\hline Guanajuato & $\begin{array}{l}\text { Ley de protección de personas defensoras de } \\
\text { derechos humanos y periodistas del estado de } \\
\text { Guanajuato }\end{array}$ & $\begin{array}{r}26 \text { de octubre de } \\
2017\end{array}$ \\
\hline Guerrero & $\begin{array}{l}\text { Ley número } 489 \text { para la protección de personas } \\
\text { en situación de riesgo del estado de Guerrero }\end{array}$ & $\begin{array}{r}26 \text { de agosto de } \\
2014\end{array}$ \\
\hline Hidalgo & $\begin{array}{l}\text { Ley de protección a personas defensoras de los } \\
\text { derechos humanos y salvaguarda de los } \\
\text { derechos para el ejercicio del periodismo }\end{array}$ & $\begin{array}{r}27 \text { de agosto de } \\
2012\end{array}$ \\
\hline Jalisco & $\begin{array}{l}\text { Ley para la protección de personas defensoras } \\
\text { de los derechos humanos y periodistas del } \\
\text { estado de Jalisco }\end{array}$ & $\begin{array}{r}17 \text { de diciembre de } \\
2016\end{array}$ \\
\hline Michoacán & $\begin{array}{l}\text { Ley para la protección de personas defensoras } \\
\text { de los derechos humanos y periodistas del } \\
\text { estado de Michoacán de Ocampo }\end{array}$ & $\begin{array}{r}14 \text { de agosto de } \\
2018\end{array}$ \\
\hline Morelos & $\begin{array}{l}\text { Ley de protección a periodistas y defensores de } \\
\text { derechos humanos del estado de Morelos }\end{array}$ & $\begin{array}{r}20 \text { de agosto de } \\
2018\end{array}$ \\
\hline Nayarit & $\begin{array}{l}\text { Ley de protección de personas defensoras de } \\
\text { derechos humanos y periodistas del estado de } \\
\text { Nayarit }\end{array}$ & 27 de julio de 2017 \\
\hline Tamaulipas & $\begin{array}{l}\text { Ley para la protección de personas defensoras } \\
\text { de los derechos humanos y periodistas para el } \\
\text { estado de Tamaulipas }\end{array}$ & $\begin{array}{r}01 \text { de diciembre de } \\
2017\end{array}$ \\
\hline Veracruz & $\begin{array}{l}\text { Ley de la comisión estatal para la atención y } \\
\text { protección de los periodistas }\end{array}$ & $\begin{array}{r}3 \text { de diciembre de } \\
2012\end{array}$ \\
\hline
\end{tabular}


La elaboración de leyes estatales de protección a periodistas son un efecto que ha permeado de lo federal a lo local. Representan un indicador de la participación de las entidades federativas en la protección de informadores. Pero ocurre que, una transición a la democracia con desiguales niveles de avance en lo local, enfrenta problemas de rezagos más amplios en algunas regiones que en otras (González \& Echeverría, 2017).

Lo anterior ocasiona que los mecanismos de protección, sean los locales o el federal, no sean implementados con la misma eficacia, ocasionando la permanencia de la violencia. Esto alimenta la desconfianza por parte de los periodistas de todo el país, quienes solicitan la protección de estos mecanismos a sabiendas de que serán más efectivas las medidas personales de autoprotección que las previstas en las leyes (De León \& González, 2020; González \& Reyna, 2019).

La gravedad de esto radica en varios aspectos puntuales. En primer lugar, la limitación de los recursos que componen los fondos de los mecanismos de protección, los cuales no son suficientes o no están disponibles cuando es necesario. En segundo lugar, el proceso burocrático, puesto que no se no actúa de oficio, sino sólo a petición de parte. En tercer lugar, la ralentización en el otorgamiento medidas de protección a los periodistas en riesgo. En cuarto sitio, los procedimientos de la implementación, demasiado previsibles para los perpetradores, consistentes en guardias con horarios programados, firmas en días específicos, registros, etcétera. En quinta posición, las sanciones que pesan sobre los mismos protegidos que, si abandonan las medidas establecidas por considerarlas poco seguras, se hacen merecedores de castigos que contemplan amonestaciones, la eliminación de las medidas y multas. En sexto lugar, la definición de periodista establecida en las leyes suele ser limitativa, pues reconoce a quienes tienen como principal actividad remunerada la actividad periodística, dejando en la indefensión a otras formas de ejercicio del oficio. Finalmente, en séptimo lugar, la ausencia de mención de la censura como causa fundamental de la violencia contra los periodistas, lo cual favorece la criminalización de las víctimas al poner en entredicho su actividad informativa (De León \& González, 2020).

Una modalidad de violencia la constituye el espionaje por medios electrónicos. Entre el año 2015 y 2016 el Estado mexicano instaló el software de espionaje Pegasus en los dispositivos de periodistas y activistas, comprado al alto costo de 438 millones de dólares por el gobierno federal. Situaciones como esta someten a un riesgo oculto a los comunicadores, pues la información que resguardan queda comprometida. A pesar de eso, tienen la necesidad de utilizar dispositivos tecnológicos para su labor profesional, con la conciencia de que permanentemente se exponen a un ataque cibernético. Es un arma de doble filo (González \& Rodelo, 2020).

Otro aspecto de la vulneración de los derechos de la comunicación, en este caso para los ciudadanos en general, fue la contrarreforma realizada por el gobierno federal en el año 2017 sobre los derechos de las audiencias. Derivado de la reforma constitucional del 2013, se estableció que el Instituto Federal de Telecomunicaciones, órgano autónomo constitucional, tutelaría los derechos de las audiencias, por lo que en uso de sus facultades constitucionales estableció los lineamientos correspondientes que fueron aprobados por el pleno (IFT, s/f; Negrete, 2017; Sánchez, 2016).

El gobierno federal impulsó una contrarreforma para desconocer el tutelaje del IFT sobre los derechos de las audiencias, liberando a los radiodifusores de observar los lineamientos emitidos. A cambio, podrían establecer un código de autorregulación. Este hecho fue interpretado como un retroceso y como una manera del gobierno federal de congraciarse con los concesionarios televisivos. Organizaciones de la sociedad civil, asociaciones académicas y actores políticos promovieron un proceso amicus curiae ante la Suprema Corte de Justicia de la Nación para ampararse ante esa decisión legislativa. El amparo fue otorgado, y el Congreso recibió la orden de no volver a legislar en contra de los derechos de las audiencias (AMEDI, 2020). 


\subsection{Regulación de la comunicación social en lo local}

Los tres momentos definitorios de lo comunicacional en el plano jurídico, revisados páginas atrás, transminaron a lo local. En las entidades federativas también se formularon leyes con el objetivo de normar aspectos relativos a los derechos y libertades de la información y la comunicación que antes del año 2000 no existían. De manera que, 20 años después del comienzo de la alternancia, es posible ver un cuerpo legal compuesto por 144 leyes estatales, a través de las cuales se va consolidando la normatividad sobre comunicación e información en los estados de la República Mexicana.

Como resultado de la revisión y el análisis formal de las leyes estatales sobre comunicación social, es posible identificar tres grandes directrices. La primera es la obligación de legislar sobre materias específicas, en cumplimiento de los preceptos constitucionales y como parte de la pertenencia al pacto federal. En esta directriz se ubican las leyes de transparencia y acceso a la información y las de protección de datos personales, que aparecen de manera irrestricta en las 32 entidades y se encuentran alineadas con las leyes federales correspondientes.

Una segunda directriz es la que corresponde a una franja más o menos amplia de preocupaciones compartidas en gran parte de las entidades. Son leyes que ayudan a ordenar aspectos relacionados con la libertad de expresión, los derechos de las audiencias, la actividad de los medios gubernamentales y la participación en las industrias audiovisuales. A pesar de ser preocupaciones compartidas en lo general, estas leyes suelen tener características específicas distintas en cada entidad, lo que permite identificar en ellas la emergencia de las agendas legislativas locales en relación a las actividades de la comunicación social.

La tercera se refiere a aspectos novedosos que muy recientemente se han incorporado a las agendas legislativas locales como los derechos digitales y el gobierno abierto. La tabla 2 muestra la distribución de las legislaciones ordenadas en categorías analíticas temáticas procedentes del análisis formal.

Tabla 2. DISTRIBUCIÓN ANALÍTICA DE LEYES LOCALES SOBRE COMUNICACIÓN SOCIAL EN MÉXICO

\begin{tabular}{|c|c|c|}
\hline Categorías de leyes & $\mathbf{f}$ & $\%$ \\
\hline 1) Rendición de cuentas y protección de datos & 65 & 45.14 \\
\hline 2) Libertad de expresión y derechos de las audiencias & 27 & 18.75 \\
\hline 3) Comunicación gubernamental e institucional & 23 & 15.97 \\
\hline 4) Medios públicos, fondos editoriales, industrias audiovisuales y publicidad & 17 & 11.81 \\
\hline 5) Derechos digitales, gobierno electrónico y abierto & 12 & 8.33 \\
\hline TOTAL & 144 & 100 \\
\hline
\end{tabular}

Podemos observar que cerca de la mitad de las leyes presentadas en la tabla 2, el $45.14 \%$, pertenecen a la primera categoría y corresponden a 32 leyes de transparencia y acceso a la información y 33 de protección de datos personales. Todas las entidades federativas tienen la obligación de contar estas legislaciones por lo que su expedición forma parte de la agenda política nacional. Este conjunto corresponde a la primera de las directrices mencionadas previamente.

Las siguientes tres categorías corresponden a leyes elaboradas para proteger la actividad periodística y los derechos de las audiencias, dar certeza jurídica a los medios públicos estatales, normar la difusión institucional, la comunicación gubernamental, la publicidad exterior y establecer normativas para el apoyo de la producción editorial y audiovisual. Se vinculan con la segunda directriz. 
Finalmente, la tercera directriz se puede observar en la última categoría, cuyo reducido porcentaje (8.33) es indicio de que sus temas son incipientes en las agendas políticas estatales. Así pues, en los estados se comienza a debatir el reconocimiento de los derechos digitales; los riesgos inherentes a la comunicación digital; las ventajas de garantizar el acceso al software de código abierto y el avance del acceso a la información, rendición de cuentas y beneficios transaccionales que ofrecen los esquemas de gobierno electrónico y abierto.

\section{Discusión. Grandes avances y pocos resultados}

El razonamiento que se ha buscado argumentar aquí es que, en materia de la protección a la libertad de expresión, existen grandes avances y, sin embargo, resultados muy pobres que dejan en entredicho los procesos de transición a la democracia.

Se plantea que los avances han sido significativos porque se ha robustecido y modernizado la legislación federal y estatal en materia de comunicación social, con relación al catálogo existente durante la segunda mitad del siglo XX. Esto es importante porque el primer paso para hacer exigibles los derechos es su reconocimiento y formalización en los instrumentos legales.

La apertura del debate sobre la transparencia y el acceso a la información al inicio de la década del 2000, la reforma electoral del 2007 y las reformas constitucionales del 2013 han sido momentos decisivos. Sirvieron para ordenar y modernizar los esquemas de la rendición de cuentas, las telecomunicaciones, los medios y los derechos ciudadanos a la información y comunicación. Éstos eran esquemas que permanecían rezagados debido a la fuerte influencia del poder mediático que impedía realizar los cambios necesarios, debido a la defensa de sus intereses políticos y económicos, en detrimento de los procesos democráticos y de los derechos ciudadanos.

Esas reformas no han sido perfectas. Han quedado vacíos -intencionales o no- que será necesario subsanar. Los procesos legislativos no son estancos, y mucho menos concluyen cuando una ley específica ha sido elaborada. Constantemente hay voces provenientes de las tres esferas sociales, a saber, la sociedad civil, el mercado y el Estado, que presionan para que sus diversas necesidades se incorporen al texto de la ley.

No obstante, el reconocimiento de los avances formales en la defensa de la libertad de expresión, quedan pendientes desafíos. Hace falta comprobar que los ordenamientos que han sido expedidos, el marco institucional que ha sido construido y los procedimientos previstos, tengan un impacto sobre el real ejercicio de las libertades de comunicación e información en México. Que realmente puedan ser practicadas sin cortapisas y sin peligro, porque están garantizadas.

Aún existe una brecha bastante amplia entre los avances jurídicos y los riesgos de expresarse libremente en el espacio público. Ello se presenta como consecuencia de la persistencia del autoritarismo en las regiones, de los intereses económicos y políticos por encima de los intereses ciudadanos en materia de comunicación social, así como de la aún no recuperada degradación de las relaciones sociales por causa de las violencias y la corrupción.

\section{Referencias bibliográficas}

AMEDI. (2020). La Asociación Mexicana de Defensorías de las Audiencias gana amparo en favor de radioescuchas y televidentes - Amedi. Recuperado el 2 de octubre de 2020 a partir de https://bit.ly/3cSxQSE

Article-19. (2020). Periodistas asesinados en México, en relación con su labor informativa. 
Recuperado el 30 de julio de 2020, a partir de https://articulo19.org/periodistasasesinados/

Beck, U. (2006). La sociedad del riesgo. México: Paidós.

Brambila, J. A. (2018). Libertad de expresión. Informe 2018. Avances y tareas pendientes para el fortalecimiento de la libertad de expresión en México. México: CASEDE.

Cantú, M. E. (2005). Medios \& poder. El papel de la radio y la televisión en la democracia mexicana. México: Norma.

Carpizo, J. (2008). La reforma del Estado en 2007 y 2008. Cuestiones constitucionales, (19), 1948.

Cepeda, D. A. (2017). Periodismo violentado en México. Entre las agresiones, la autocensura y el bajo salario en provincia. Argumentos, 30(85), 39-61.

De León, S. (2003). La construcción del acontecer. Análisis de las prácticas periodísticas. México: CONEICC, Universidad de Guadalajara, Universidad Autónoma de Aguascalientes.

De León, S. (2011). Comunicación pública, transición política y periodismo en México: el caso de Aguascalientes. Comunicación y Sociedad, N.E.(15), 43-69.

De León, S. (2020). Legislación sobre Comunicación Social en el Espacio Subnacional. El Caso de México. Doxa Comunicación, 31 (preprint), 1-19. Recuperado a partir de https://bit.ly/3kXjgeV

De León, S., Bravo, A., \& Duarte, E. M. (2018). Entre abrazos y golpes... Estrategias subpolíticas de periodistas mexicanos frente al riesgo. Sur Le Journalisme, 7, 114-129.

De León, S., \& González, R. (2020). Reportear en el desamparo: Análisis de las medidas de protección a periodistas en México desde el contexto local. Revista de Comunicación, 19(2), 87109. Recuperado a partir de https://doi.org/10.26441/RC19.2-2020-A5

Del Palacio, C. (2015). Periodismo impreso, poderes y violencia en Veracruz 2010-2014. Estrategias de control de la información. Comunicación y Sociedad (0188-252X), 24, 19-46.

Del Palacio, C. (2018). Callar o morir en Veracruz. Violencia y medios de comunicación en el sexenio de Javier Duarte (2010-2016). México: Juan Pablos.

Espino, G., \& Mendoza, E. (2015). Los gobernadores, enclaves del autoritarismo en México. Sometimiento y subordinación de los medios de comunicación locales. México: Fontamara.

Esteinou, J. (2009). La reproducción del poder comunicativo en México a través de la Ley Televisa. Polis: Investigación y Análisis Sociopolítico y Psicosocial, 5(1), 51-90.

FEADLE. (2020). Fiscalía Especial para la Atención de Delitos cometidos contra la Libertad de Expresión Actualizado al mes de Junio de 2020.

González de Bustamante, C. (2014). Professionalism in flux: journalists' self reflections about their work in nothern Mexico. En Horizontes de investigación sobre Estudios de Periodismo. Ciudad de México.

González, R. A. (2013). Economically-Driven Partisanship -Official Advertising and Political Coverage in Mexico: The Case of Morelia. Journalism and Mass Communication, 3(1), 14-33.

González, R. A., \& Echeverría, M. (2017). A medio camino. El sistema mediático mexicano y su irregular proceso de modernización. Revista Mexicana de Opinión Pública, (24), 35-51. Recuperado a partir de https://doi.org/10.22201/fcpys.24484911e.2018.24.60437

González, R. A., \& Reyna, V. H. (2019). They don't trust us; they don't care if we're attacked": Trust and risk perception in Mexican journalism. Communication \& Society, 32(1), 147-160. Recuperado el 14 de marzo de 2019 a partir de https://doi.org/10.15581/003.32.1.147-160 
González, R. A., \& Rodelo, F. V. (2020). Double-edged knife: practices and perceptions of technology and digital security among Mexican journalists in violent contexts. Tapuya: Latin American Science, Technology and Society, 0(0), 1-21. Recuperado a partir de https://doi.org/10.1080/25729861.2020.1746502

Hernández, M. E. (2016). Relaciones prensa-gobierno en las administraciones panistas en Jalisco: golpe de timón y reviraje (1995-2012). En 18 años de gobiernos panistas en Jalisco. Siete ensayos académicos (pp. 71-89). México: ITESO.

Huerta, W. D., \& Becerra, J. (2016). La reforma del sector de telecomunicaciones en México: una lectura desde el paradigma de la complejidad. Razón y Palabra, 20(95), 487-512.

IFT. (s/f). Lineamientos generales sobre los derechos de las audiencias. México: Instituto Federal de Telecomunicaciones.

Lay, I. T. (2013). Medios electrónicos de comunicación, poderes fácticos y su impacto en la democracia en México. Revista Mexicana de Ciencias Políticas y Sociales, 58(217), 253-268. Recuperado a partir de https://doi.org/10.1016/s0185-1918(13)72284-0

Madrazo, A., \& Zambrano, J. L. (2007). La ley de Televisa ante la Suprema Corte. Isonomía, (26), 71-100.

Maldonado, P. (2018). Relación prensa-Estado, consideraciones hacia la regulación de la publicidad oficial en México . Estudio regional Press-State relations in Mexico , considerations towards the regulation of official advertising : Regional study. Question, 1(58), 1-20.

Martínez, S., \& Ramos, D. N. (2020). Periodismo colaborativo: Tejiendo Redes en disputa por la palabra y la agenda informativa. Comunicación y Sociedad, (e7608), 1-22. Recuperado a partir de https://doi.org/10.32870/cys.v2020.7608

Merchant, D. D. (2017). Censura y manipulación de la información en Baja California. Sur Le Journalisme, 7, 65-83.

Negrete, J. (2017). Derechos de las audiencias son un logro que no debe regatearse - Amedi. Recuperado el 2 de octubre de 2020 a partir de https://bit.ly/2SnEK8U

Orozco, R. (2007). Relaciones prensa-gobierno en Tepic: hacia una caracterización de prácticas predominantes en el periodismo local de México. Universidad de Guadalajara.

Ramírez, J. (2018). Sin justicia y sin prevención: seguiremos enterrando colegas. En R. Trejo \& J. Trejo-Quintana (Eds.), Persecusión a periodistas (pp. 237-252). México: Comisión Nacional de los Derechos Humanos.

Ramos, E., Márquez, L., \& Sánchez, M. (2008). Análisis comparativo de la reforma electoral constitucional y legal 2007-2008. México: IFE.

Reguillo, R. (2013). De las violencias: caligrafía y gramática del horror. Desacatos. Revista de Ciencias Sociales.

Rodelo, F. V. (2009). Periodismo en entornos violentos: el caso de los periodistas de Culiacán, Sinaloa. Comunicación y Sociedad, (12), 101-118.

Rovira, G. (2017). Activismo en red y multitudes conectadas. Comunicación y acción en la era de Internet. México: Icaria.

Sánchez, K. (2016). Sobre los derechos de las audiencias en México On the rights of media audiences in Mexico. Comunicación y Sociedad, 27, 188-252.

UNESCO. (2018). Sancionar el delito, no la verdad. París: UNESCO. 
Van seis periodistas asesinados en México en 2020. (2020). La Jornada. México. Recuperado el 30 de julio de 2020 a partir de https:/www.jornada.com.mx/ultimas/politica/2020/05/17/van-seisperiodistas-asesinados-en-mexico-en-2020-442.html 